\title{
The hydrologic record of karst systems: linking soil moisture to the carbon isotope signatures of soils above the Blue Spring cave system
}

\author{
Yuchen Liu ${ }^{1} \cdot$ Jessica L. Oster $^{2} \cdot$ Jennifer L. Druhan ${ }^{1}$
}

Received: 11 April 2017/Revised: 24 April 2017/Accepted: 24 April 2017/Published online: 4 May 2017

(C) The Author(s) 2017. This article is an open access publication

\begin{abstract}
Speleothem carbonates are precipitated continuously from inorganic carbon dissolved in seepage water infiltrating from the land surface, that reflects a mixture of atmospheric $\mathrm{CO}_{2}$, respired soil carbon, and epikarst sources, each with distinct $\delta^{13} \mathrm{C}$ values. To aid in deconvolving these signatures, soil samples were collected above the Blue Spring cave system in Sparta, Tennessee, USA and subjected to a series of incubation experiments, in order to constrain the correlation between $\mathrm{CO}_{2}$ respiration rates and soil moisture. This relationship is used to parameterize a simple mixing model which predicts the relationship between $\delta^{13} \mathrm{C}$ and soil moisture in fluids infiltrating into the underlying cave system.
\end{abstract}

Keywords Speleothem $\cdot \delta^{13} \mathrm{C} \cdot \mathrm{CO}_{2}$ respiration $\cdot$ Soil moisture

\section{Introduction}

Karst systems constitute approximately $20 \%$ of the terrestrial Earth surface and experience distinct hydrogeochemical alteration as a result of the reactivity between limestone and rainwater. Cave systems formed within the subsurface of these landscapes record a history of mineral-

11th International Symposium on Geochemistry of the Earth's Surface.

Yuchen Liu

liu305@illinois.edu

1 Department of Geology, University of Illinois Urbana Champaign, Champaign, IL, USA

2 Department of Earth and Environmental Science, Vanderbilt University, Nashville, TN, USA water-microbe interactions through the deposition of secondary minerals. Speleothem carbonates formed in the caves offer a key means of unraveling the hydrologic conditions of the past in that they are often continuously formed over a long period of time and can be precisely dated. Previous studies have suggested that the carbon isotopic compositions $\left(\delta^{13} \mathrm{C}\right)$ in speleothem carbonates are controlled by the isotopic signature of dissolved $\mathrm{CO}_{2}$ in seepage water, which is a function of the climate and surface hydrologic cycle (e.g. Genty et al. 2001). This signal is subsequently modified to varying degrees within the epikarst through interactions with host rocks and deep sources of organic matter (e.g. Oster et al. 2010). Thus the carbon isotopic composition of speleothems may offer a means of revealing past climate changes, but further research combining the effects of reactivity and transport are needed.

$\mathrm{CO}_{2}$ dissolved into the seepage water which interacts with epikarst has two sources: atmospheric $\mathrm{CO}_{2}$ and $\mathrm{CO}_{2}$ respired by soil microorganisms. Since the $\delta^{13} \mathrm{C}$ signature of atmospheric $\mathrm{CO}_{2}$ is fairly constant $(\sim-7 \%)$ over the time scale of water infiltrating through soil, variations in the $\delta^{13} \mathrm{C}$ of this fluid are primarily controlled by the amount of $\mathrm{CO}_{2}$ respired within the soil and the $\delta^{13} \mathrm{C}$ of the labile organic soil carbon. Since the $\delta^{13} \mathrm{C}$ of the respired $\mathrm{CO}_{2}$ can be affected by the type of vegetation $(\mathrm{C} 3$ or $\mathrm{C} 4)$, where $\mathrm{C} 3$ plants have a lower $\delta^{13} \mathrm{C}$ signature $(-24 \%$ o to $-34 \%$ ) than $\mathrm{C} 4$ plants $(-6 \%$ to $-19 \%$ ) (e.g. Deines 1980), distinctions in the $\delta^{13} \mathrm{C}$ recorded in speleothems could reflect different ecosystems in different periods of time (e.g. Dorale et al. 1998). In addition, given the large C isotopic fractionation between vegetation and atmospheric $\mathrm{CO}_{2}$, changes in soil respiration rates can affect the mass balance between these two sources of $\mathrm{CO}_{2}$ and thus the isotopic signature of the mixed fluid sample. Specifically, 
when the respiration rate is high, $\mathrm{CO}_{2}$ dissolved in seepage water should appear lower, and vice versa. As the seepage water infiltrates below the soil layer, dissolution of the host carbonate will dampen the $\delta^{13} \mathrm{C}$ signature. Several aspects have been proposed explaining the variations in speleothem $\delta^{13} \mathrm{C}$. Some studies have suggested that the respiration record is not totally erased, and thus may serve as an indicator of past changes in the hydrologic cycle (e.g. Oster et al. 2015). However, a recent study suggests that such changes can only be recorded in the speleothems when environments are described by low mean annual precipitation and temperature (Breecker 2017).

Previous studies have focused on a variety of factors that affect soil respiration rates (temperature, microbial community, $\mathrm{pH}$, organic carbon composition, soil texture, and moisture). Among these, soil moisture directly reflects the surface hydrologic cycle (and ultimately climate changes), and influences the velocity at which water seeps into the underlying caves. The correlation between soil moisture and respiration rates has been studied both in lab settings and in situ soil profiles. It is commonly demonstrated that these parameters are positively correlated in arid and semi-arid systems, and negatively correlated when soil approaches saturation (e.g. Howard and Howard 1993). Multiple processes have been proposed for the cause of this correlation. A common explanation is that at lower soil moistures, water deficiency inhibits the proficiency of the microbial communities to respire. Under dry conditions, microbes are prone to enter a dormant state, reserving energy for more favorable conditions, and resulting in a lower respiration rate at lower soil moistures. In contrast, at higher soil moistures, $\mathrm{O}_{2}$ concentrations in the soils become limiting as a result of both the low equilibrium $\mathrm{O}_{2}$ concentration in the water and the orders of magnitude difference in the diffusion coefficient of oxygen in a liquid phase verses a gas phase. Thus, when soils approach full saturation, oxygen fugacity is insufficient to support a high oxidation rate of organic carbon, which is reflected as a negative correlation at higher soil moistures (e.g. Skopp et al. 1990).

The relationship between soil moisture and respired $\mathrm{CO}_{2}$ also exhibits strong transient fluctuations. In particular, an extremely high soil respiration rate (manifested as a large pulse of $\mathrm{CO}_{2}$ ) is observed when a long period of drought is followed by a large precipitation event (also known as the Birch effect). The validity and significance of the Birch effect has been demonstrated in previous studies over timescales of days to months, suggesting $\mathrm{CO}_{2}$ concentration pulses large enough to support abrupt, transient shifts in the $\delta^{13} \mathrm{C}$ of dissolved soil $\mathrm{CO}_{2}$ might be recorded by speleothem formation.

In this study, soil core samples were collected directly above the Blue Spring cave system in Sparta, Tennessee, USA, an active, instrumented cave system. Soil samples were incubated at a range of fluid saturations to constrain the relationship between soil moisture and $\mathrm{CO}_{2}$ respiration rate in order to predict the maximum range of the $\delta^{13} \mathrm{C}$ of water entering the epikarst above the cave. These data will be applied to calibrate parameter values in an isotope-enabled reactive transport framework (CrunchTope, Steefel et al. 2015) to advance our understanding of the connection between surface hydrologic variability and speleothem composition.

\section{Methods}

Blue Spring Cave is a developed cave system with approximately $62 \mathrm{~km}$ of mapped passage. Though much of the cave is covered with sandstones and conglomerates which prevent water infiltration and speleothem formation, seepage water is found on the edges of the cave system where the cap rock is absent, resulting in active speleothem growth. Monitoring devices have been installed both above and in the cave since June 2013 recording air temperature and humidity for both surface air and cave air, rainfall amount, soil temperature and moisture, $\mathrm{pCO}_{2}$ and drip rate in the cave. Drip water in the cave is collected and measured monthly for chemical concentrations and $\delta^{13} \mathrm{C}$. Soil gas wells installed above the cave enable sampling and measurement of gas concentrations and $\delta^{13} \mathrm{C}$ of soil gas as a function of depth.

Soil core samples were taken near the gas wells installed at the edge of the cave system. Cores were divided into four subsamples based on depths $(0-10.7 \mathrm{~cm}, 10.7-21.3 \mathrm{~cm}$, $21.3-32.0 \mathrm{~cm}, 32.0-40.0 \mathrm{~cm}$ ), carefully sealed, and shipped to the University of Illinois Urbana-Champaign. All samples were stored at 3 degrees Celsius for approximately two months before pretreatments for incubation. Pretreatment involved air-drying for two weeks to reach residual water saturation, and sieving with a $2-\mathrm{mm}$ mesh size.

Water holding capacity of the soil samples was determined prior to incubation by recording the mass of water adding to weighed air-dried soil samples until they became fully saturated. Three 75-gram air-dried subsamples are taken from each depth, and individually placed into 237-mL glass vessels (AnchorGlass). The three subsamples were subjected to distinct soil moisture contents of $30 \%$, $60 \%$, and $100 \%$ water holding capacity. Polyethylene tubing (McMaster-Carr) was connected to the vessels through two ports on each cap, sealed with epoxy to prevent gas leakage, and connected with luer-loc valves (Nordson Medical) to allow for sampling. Each vessel was purged with $\mathrm{CO}_{2}$ free air for over 10 times the volume of the jars after they were sealed. $\mathrm{CO}_{2}$ concentrations in the headspace were measured using an Infrared Gas Analyzer (LICOR-8100) once every $24 \mathrm{~h}$. The vessels were again purged with $\mathrm{CO}_{2}$ free air after every sampling processes. 


\section{Results}

Respiration patterns are consistent across different depths of the soil profile and with different soil moistures (Fig. 1), in agreement with previous studies (e.g. Schimel et al. 1999). Respiration rates for the $60 \%$ soil moisture (black lines) are higher than $30 \%$ soil moisture (red lines) and $100 \%$ soil moisture (blue lines) for all depths of soil samples, as a result of microbe dormancy at lower moisture, and insufficient $\mathrm{O}_{2}$ at higher moisture. A large $\mathrm{CO}_{2}$ pulse is observed after $48 \mathrm{~h}$ of incubation, and it levels out to reach an equilibrium after approximately $200 \mathrm{~h}$, consistent with the Birch effect. The transient peak values are two to three times higher than equilibrium respiration rates. Also, the largest differences in respiration rate as a function of soil moisture is observed in the shallower depths, while for deeper soils, moisture has little effect on respiration rates.

\section{Discussion}

Based on the incubation results, it is clear that $\mathrm{CO}_{2}$ respiration rates are highly dependent on soil moisture for the samples collected from the Blue Spring site. This implies that changes in soil moisture at the field site (rainfall events, drought, etc.), will result in different amounts of respired $\mathrm{CO}_{2}$, resulting in a changing $\mathrm{CO}_{2}$ concentration of the fluid infiltrating the soil at different time periods. $\mathrm{CO}_{2}$ from both the atmosphere and this respiration source dissolve into the water infiltrating through the soil zone and form bicarbonate $\left(\mathrm{HCO}_{3}{ }^{-}\right)$and carbonate $\left(\mathrm{CO}_{3}{ }^{2-}\right)$, while changing the $\mathrm{pH}$ of the solution.

As a result, increased $\mathrm{CO}_{2}$ partial pressure in the soil zone results in a more acidic, reactive fluid infiltrating the epikarst, and this reactivity is primarily controlled by soil respiration rate. This water ultimately moves into the underlying cave where secondary carbonate minerals precipitate to form speleothems. Thus it is plausible that the soil moisture control on soil respiration rate may be preserved in the speleothem record. However modification of $\delta^{13} \mathrm{C}$ signatures through carbonate dissolution and precipitation within the epikarst must also be examined.

The inorganic carbon dissolved in the water infiltrating the soil will have the isotopic signature of the gas phase $\mathrm{CO}_{2}$ in the soil zone. The gas phase $\mathrm{CO}_{2}$ in the soil pores is a mixture of respired $\mathrm{CO}_{2}$ with $\delta^{13} \mathrm{C}$ similar to the organic carbon in the soil $(\sim-20 \%)$, and atmospheric $\mathrm{CO}_{2}$ which has a $\delta^{13} \mathrm{C}=\sim-7 \%$. Therefore, the mixing of these two sources should result in a $\delta^{13} \mathrm{C}$ signature of the water entering the epikarst which reflects changes in the amount of $\mathrm{CO}_{2}$ respired.

A mass balance calculation is presented which combines the correlation between soil moisture and respiration rates
Fig. $1 \mathrm{CO}_{2}$ respiration rates at different times for a $0-10.7 \mathrm{~cm}$; b $10.7-21.3 \mathrm{~cm}$; c $21.3-32.0 \mathrm{~cm}$; d $32.0-40.0 \mathrm{~cm}$ depths of soil. Red, black, and blue symbols and lines represent 30\%, 60\%, and $100 \%$ soil moisture capacity, respectively
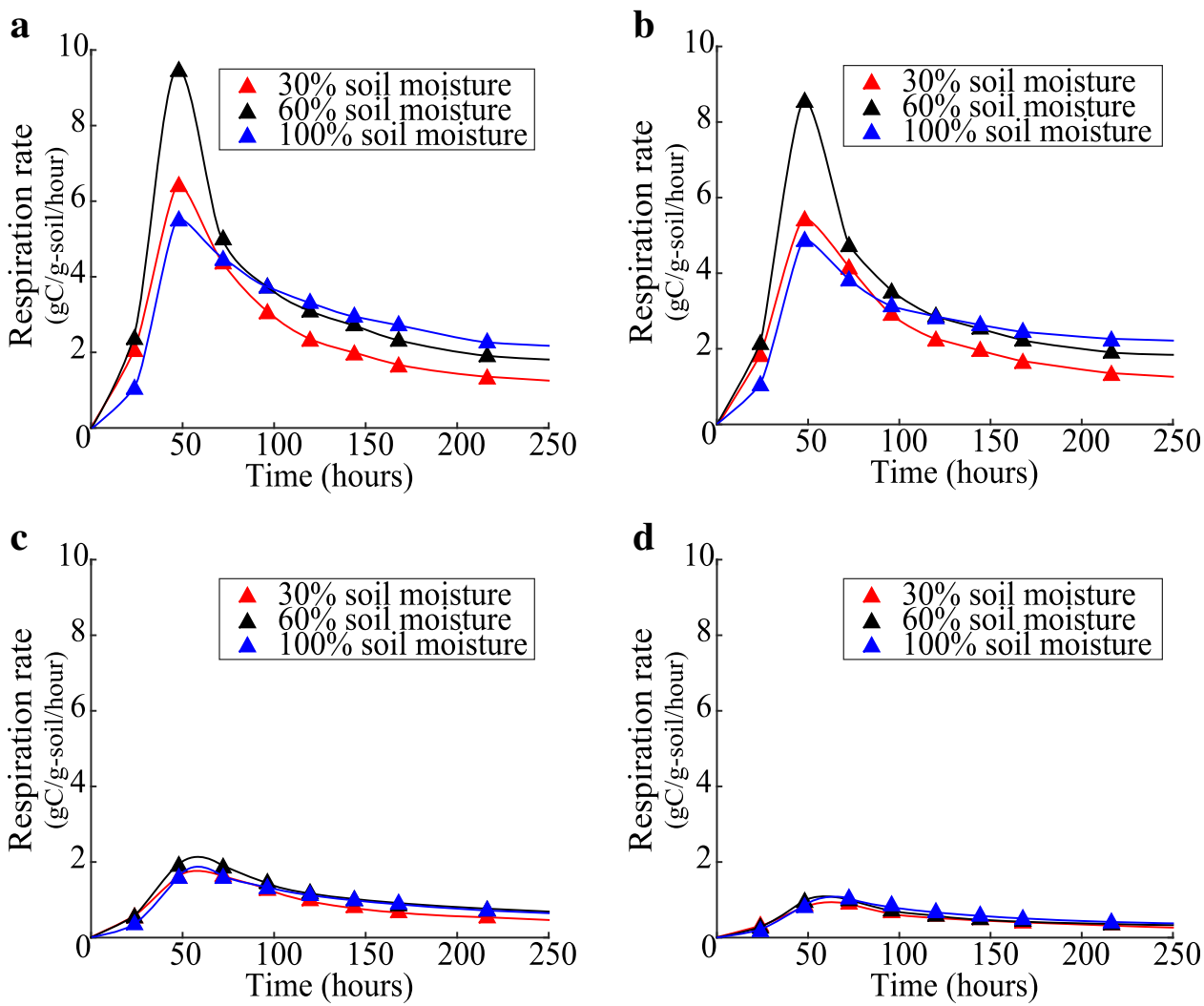
Fig. 2 a Diagram of the mixing box model; $\mathbf{b}$ predicted $\delta^{13} \mathrm{C}$ of the fluid entering the epikarst as a function of soil moisture
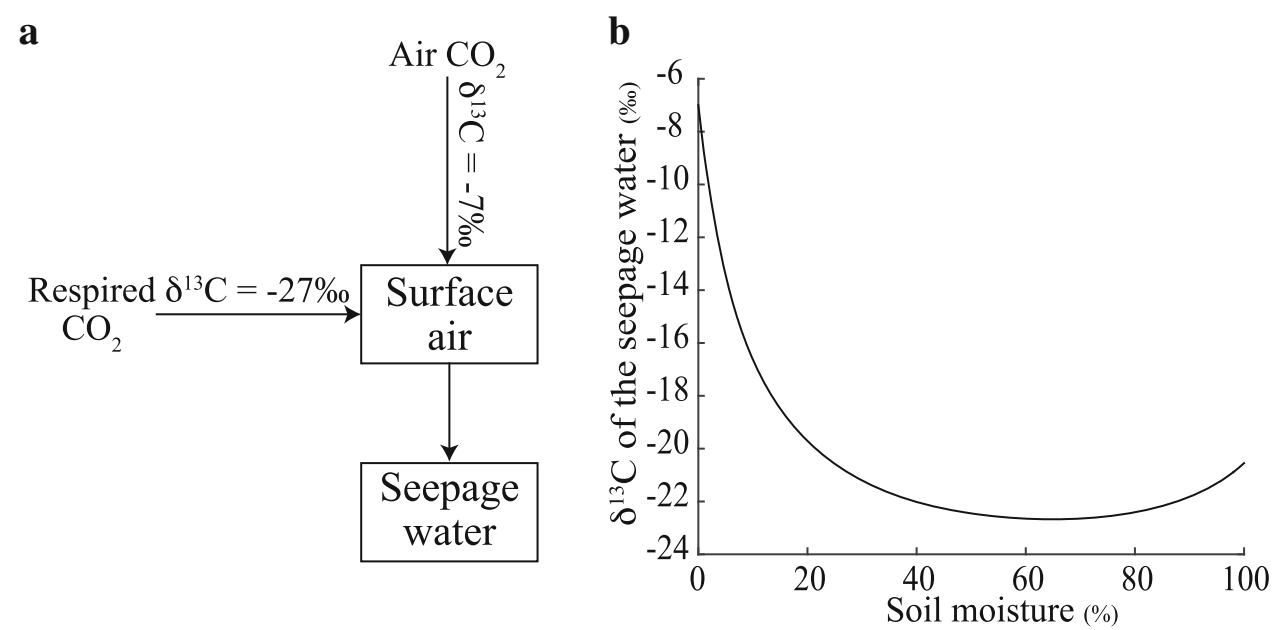

(Fig. 1) and the correlation between respiration rates and $\delta^{13} \mathrm{C}$ of the fluid infiltrating the epikarst, following a simple box model approach (Fig. 2a). The model shows the relationship between soil moisture and $\delta^{13} \mathrm{C}$ of fluid entering the epikarst (Fig. 2b). $\delta^{13} \mathrm{C}$ of the respired $\mathrm{CO}_{2}$ is assumed to be $-20 \%$, and atmospheric $\delta^{13} \mathrm{C}$ is set to $-7 \%$. The respired $\mathrm{CO}_{2}$ concentration used in this simulation is taken from the data measured after $48 \mathrm{~h}$ of incubation for the 0-10.7 cm soil, extrapolating the three datapoints to the whole moisture range with polynomial fitting, and diluted $10 \times$ to approximate gas diffusion across an in situ soil profile. Results show that in arid and semi-arid conditions, the $\delta^{13} \mathrm{C}$ of the soil water is negatively correlated with soil moisture, and the trend reverses when soils approach saturation. Even though respiration might not be a controlling factor in environments such as the Blue Spring cave system, which are subject to large annual precipitation rates, the ability to deconvolve the influence of respiration is vital in interpreting speleothem $\delta^{13} \mathrm{C}$ when applying the model to other karst systems.

\section{Conclusions}

Soil incubation experiments were conducted for samples taken above Blue Spring cave system in Sparta, Tennessee, USA, to better understand the relationship between respiration rate and soil moisture. The results are related to $\delta^{13} \mathrm{C}$ of the fluid exiting the soil layer and infiltrating the epikarst with a simplified mixing model, resulting in a first order prediction of how we may interpret the changes in carbon isotopic composition of speleothems in the underlying cave.

Acknowledgements This work was supported by the US National Science Foundation, project EAR-1600931. On behalf of all authors, the corresponding author states that there is no conflict of interest.
Open Access This article is distributed under the terms of the Creative Commons Attribution 4.0 International License (http://creative commons.org/licenses/by/4.0/), which permits unrestricted use, distribution, and reproduction in any medium, provided you give appropriate credit to the original author(s) and the source, provide a link to the Creative Commons license, and indicate if changes were made.

\section{References}

Breecker DO (2017) Atmospheric $\mathrm{pCO}_{2}$ control on speleothem stable carbon isotope compositions. Earth Planet Sci Lett 458:58-68. doi:10.1016/j.epsl.2016.10.042

Deines P (1980) The isotopic composition of reduced organic carbon. In: Fritz P, Fontes JC (eds) Handbook of environmental isotope geochemistry, vol 1. Elsevier, Amsterdam, pp 329-406

Dorale JA, Edwards RL, Ito E, González LA (1998) Climate and vegetation history of the midcontinent from 75 to $25 \mathrm{ka}$ : a speleothem record from Crevice Cave, Missouri, USA. Science 282:1871. doi:10.1126/science.282.5395.1871

Genty D, Baker A, Massault M et al (2001) Dead carbon in stalagmites: carbonate bedrock paleodissolution vs. ageing of soil organic matter. Implications for ${ }^{13} \mathrm{C}$ variations in speleothems. Geochim Cosmochim Acta 65:3443-3457. doi:10. 1016/S0016-7037(01)00697-4

Howard DM, Howard PJA (1993) Relationships between $\mathrm{CO}_{2}$ evolution, moisture content and temperature for a range of soil types. Soil Biol Biochem 25:1537-1546. doi:10.1016/00380717(93)90008-Y

Oster JL, Montañez IP, Guilderson TP et al (2010) Modeling speleothem $\delta^{13} \mathrm{C}$ variability in a central Sierra Nevada cave using $14 \mathrm{C}$ and $87 \mathrm{Sr} / 86 \mathrm{Sr}$. Geochim Cosmochim Acta 74:5228-5242. doi:10.1016/j.gca.2010.06.030

Oster JL, Montañez IP, Santare LR et al (2015) Stalagmite records of hydroclimate in central California during termination 1. Quat Sci Rev 127:199-214. doi:10.1016/j.quascirev.2015.07.027

Schimel JP, Gulledge JM, Clein-Curley JS et al (1999) Moisture effects on microbial activity and community structure in decomposing birch litter in the Alaskan taiga. Soil Biol Biochem 31:831-838. doi:10.1016/S0038-0717(98)00182-5

Skopp J, Jawson MD, Doran JW (1990) Steady-state Aerobic microbial activity as a function of soil water content. Soil Sci Soc Am J 54:1619-1625. doi:10.2136/sssaj1990.03615995005400060018x

Steefel CI, Appelo CAJ, Arora B et al (2015) Reactive transport codes for subsurface environmental simulation. Comput Geosci 19:445-478. doi:10.1007/s10596-014-9443-x 